\title{
The cricoid cartilage and the esophagus are not aligned in close to half of adult patients
}

\author{
[Le cartilage cricoïde et l'asophage ne sont pas alignés chez près de la moitié \\ des adultes]
}

Kevin J. Smith MD, ${ }^{*}$ Shayne Ladak MD, $†$ Peter T.-L. Choi MD FrCPC, ${ }^{*}$ Julian Dobranowski MD FrCPC $†$

Purpose: To determine the frequency and degree of lateral displacement of the esophagus relative to the cricoid cartilage ("cricoid") using computed tomography (CT) images of normal necks.

Methods: Fifty-one cervical CT scans of clinically normal patients were reviewed retrospectively. Esophageal diameter, distance between the midline of the cricoid and the midline of the esophagus, and distance between the lateral border of the cricoid and the lateral border of the esophagus were measured.

Results: Lateral esophageal displacement was observed in 49\% (25/5 I) of CT images. When present, the mean length of displaced esophagus relative to the midline of the cricoid was $3.3 \mathrm{~mm} \pm \mathrm{SD}$ $1.3 \mathrm{~mm}$. Of those with lateral displacement, $64 \%$ had esophageal displacement beyond the lateral border of the cricoid (mean 3.2 $\mathrm{mm} \pm \mathrm{SD} 1.2 \mathrm{~mm}$ ). There is a relatively normal distribution of the grouped measures of percentage of esophageal diameter that is displaced. Of those with displacement, $48 \%$ had over 15\% of the total width of the esophagus displaced laterally and $20 \%$ had over $20 \%$ of the esophageal width displaced laterally.

Conclusion: There is a $49 \%$ frequency of some degree of lateral displacement of the esophagus relative to the cricoid.

Objectif : Déterminer la fréquence et le degré de déplacement latéral de l'œsophage relativement au cartilage cricoïde ("cricoïde») en utilisant les images tomodensitométriques cervicales normales.

Méthode : Cinquante et une images de tomodensitométrie cervicale de patients cliniquement normaux ont été revues rétrospectivement. Le diamètre œsophagien, la distance entre la ligne médiane du cricoïde et celle de l'œsophage et la distance entre le bord latéral du cricoïde et celui de l'œsophage ont été mesurées.

Résultats : Le déplacement latéral de l'œsophage a été observé dans $49 \%$ (25/5I) des images. Lorsqu'il était présent, il était en moyenne de 3,3 mm $\pm 1,3 \mathrm{~mm}$ d'écart type par rapport à la ligne médiane du cricoïde. Soixante-quatre pour cent des déplacements latéraux de l'œsophage allaient au delà du bord latéral du cricoïde (moyenne de 3,2 $\mathrm{mm} \pm 1,2 \mathrm{~mm}$ d'écart type). Nous avons noté une distribution relativement normale des mesures groupées de pourcentage de diamètre œsophagien déplacés. De ces déplacements, $48 \%$ présentaient plus de $15 \%$ de la largeur totale de l'œsophage déplacé latéralement et $20 \%$ avaient plus de $20 \%$ de déplacement.

Conclusion : La fréquence de déplacement latéral de l'œsophage d'un certain degré par rapport au cricoïde est de $49 \%$.

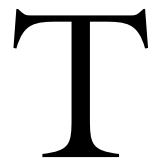

HE concept of cricoid pressure (CP) was introduced by Sellick in $1961 .^{1}$ Since then it has become a standard of practice by most anesthesiologists as a technique employed to prevent passive regurgitation and aspiration of gastric contents during the induction of anesthesia in patients at high risk for regurgitation..$^{2,3}$ However, there continues to be controversy regarding the safety and efficacy of $\mathrm{CP}^{4,5}$ In fact, a previous study reported that $10 \%$ of the 139 anesthesiologists surveyed had witnessed regurgitation despite the application of CP. ${ }^{6}$

There are several possible explanations for the failure of CP to prevent regurgitation of gastric contents. These include incorrect application of cricoid pressure, ${ }^{7,8}$ application of insufficient pressure, ${ }^{6,8}$ anatomical changes with $\mathrm{CP}^{9}$ or perhaps anatomical differences between individuals. There have been no radiological or anatomical studies assessing anatomical

From the Departments of Anesthesia* and Radiology, $\uparrow$ St. Joseph's Healthcare and McMaster University, Hamilton, Ontario, Canada. Address correspondence to: Dr. Kevin Smith, Department of Anesthesia, McMaster University, 1200 Main Street West, Room HSC-

2U1, Hamilton, Ontario L8N 3Z5, Canada. Phone: 905-521-2100, ext. 75170; Fax: 905-523-1224; E-mail: kevjo@sympatico.ca Address requests for reprints to: Dr. Peter Choi, Department of Anesthesia, McMaster University, 1200 Main Street West, Room

HSC-2U7, Hamilton, Ontario L8N 3Z5, Canada. E-mail: choip@mcmaster.ca

Accepted for publication September 12, 2001.

Revision accepted January 16, 2002. 
TABLE Baseline characteristics of patients studied

\begin{tabular}{ll}
\hline Age $(\mathrm{yr})^{*}$ & $53 \pm 18$ \\
Gender (male : female) & $27: 24$ \\
Esophageal diameter $(\mathrm{mm})^{*}$ & $23.7 \pm 5.8$ \\
Indication for CT scan $\dagger$ & \\
$\quad$ follow-up lymphoma & $17(33.3)$ \\
$\quad$ rule out neck mass & $10(19.6)$ \\
$\quad$ rule out thyroid mass & $3(5.9)$ \\
neck pain & $2(3.9)$ \\
lymphadenopathy & $4(7.8)$ \\
parotid tumour & $4(7.8)$ \\
$\quad$ other & $11(21.6)$ \\
\hline
\end{tabular}

*Values are expressed as mean \pm standard deviation; †Values are expressed as absolute number and percentage of total population in parentheses; $\mathrm{CT}=$ computed tomography.

differences between individuals at the level of the cricoid cartilage (hereafter abbreviated as "cricoid"). The purpose of this study was to retrospectively review computed tomography (CT) scans of the neck to determine if there is variation between individuals in the anatomical relationship between the cricoid and esophagus that could potentially explain reported failures of CP.

\section{Methods}

We conducted a retrospective review of all cervical CT scans done at St. Joseph's Healthcare, Hamilton, Ontario, Canada between November 1, 2000 and February 14, 2001. Exclusion criteria included age less than one; spaceoccupying pathology anterior to the vertebral body at the level of the cricoid or within one intervertebral disk space; or a previous history of cervical radiation, laryngectomy, esophagectomy, or thyroidectomy.

The level of the cricoid was determined as those images immediately inferior to the thyroid cartilage and superior to the thyroid gland. If the esophagus was not distinguishable from the inferior pharyngeal constrictor muscle at the level of the cricoid, it was identified on an image above and below and its position extrapolated. We measured the distance from the midline of the cricoid to the midline of the esophagus, the distance from the lateral border of the cricoid to the lateral border of the esophagus, and the diameter of the esophagus. All measurements were in millimetres. The relative displacement of the esophagus to the cricoid was recorded as none, leftward, or rightward.

\section{Results}

Ninety-two CT scans were completed between November 1, 2000 and February 14, 2001. Sixteen were unavailable for viewing and 25 met the exclusion criteria; therefore, 51 scans were available for review.

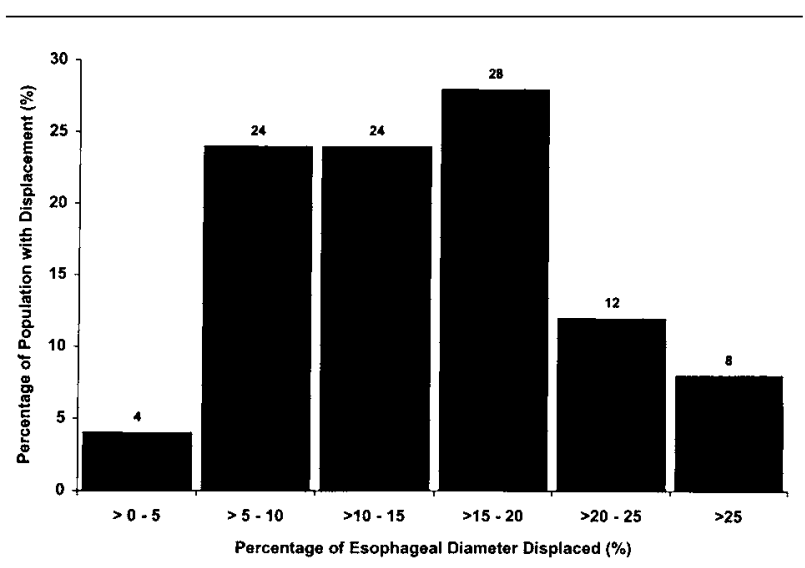

FIGURE 1 Histogram of percentage of population with lateral displacement of the esophagus categorized by the extent of esophageal diameter displaced.

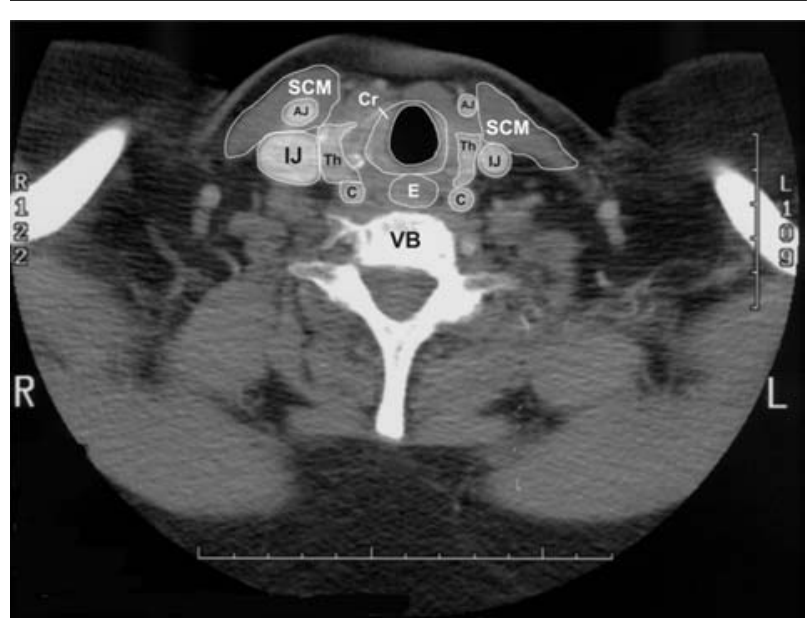

FIGURE 2 Computed tomography of the neck and line drawing demonstrating $1.5 \mathrm{~mm}$ of leftward lateral esophageal displacement. $\mathrm{AJ}=$ anterior jugular vein; $\mathrm{C}=$ carotid artery; $\mathrm{Cr}=$ cricoid cartilage; $\mathrm{E}=$ esophagus; $\mathrm{IJ}=$ internal jugular vein $; \mathrm{SCM}=$ sternocleidomastoid muscle; $\mathrm{Th}=$ thyroid gland; $\mathrm{VB}=$ vertebral body.

The Table summarizes the baseline characteristics of the patients studied. There were no statistically significant differences in age, gender, or esophageal diameter between populations with and without lateral esophageal displacement, based on chi-squared tests.

Lateral esophageal displacement was seen in $49 \%$ $(25 / 51)$ of the CT images. Of those displaced, $92 \%$ were displaced leftward and $8 \%$ were displaced rightward. When present, the length of displaced esopha- 


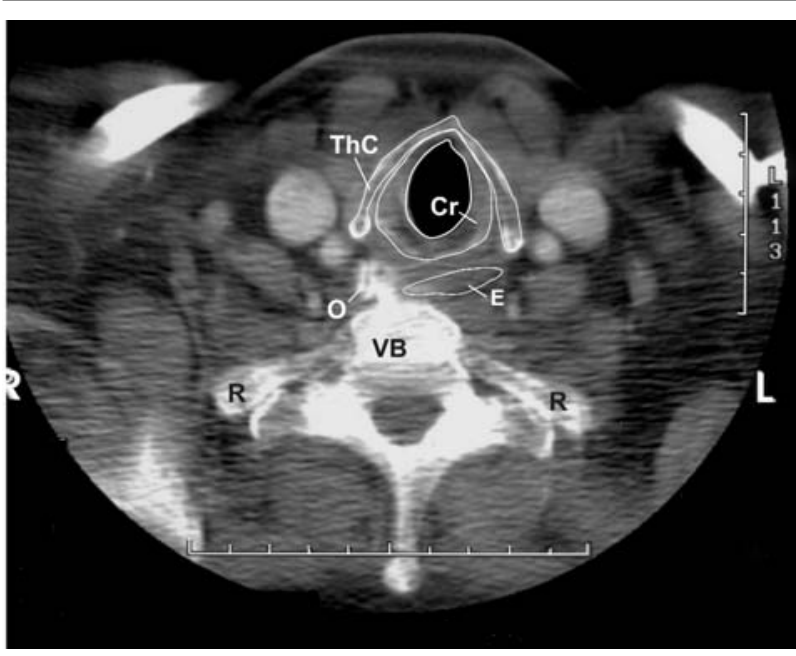

FIGURE 3 Computed tomography of the neck and line drawing demonstrating a vertebral body osteophyte and nearly complete leftward esophageal displacement. $\mathrm{Cr}=$ cricoid cartilage; $\mathrm{E}=$ esophagus; $\mathrm{O}=$ osteophyte; $\mathrm{R}$ = first rib; ThC = thyroid cartilage; $\mathrm{VB}=$ vertebral body.

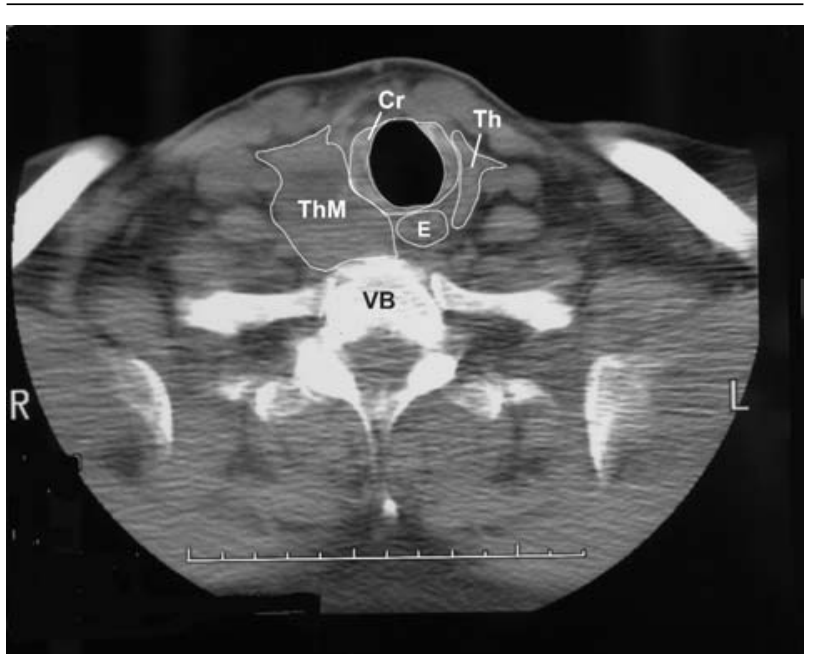

FIGURE 4 Computed tomography of the neck and line drawing demonstrating a right-sided thyroid tumour and nearly complete leftward esophageal displacement. $\mathrm{Cr}=$ cricoid cartilage; $\mathrm{E}=$ esophagus; $\mathrm{Th}=$ thyroid gland; $\mathrm{ThM}=$ thyroid mass; $\mathrm{VB}=$ vertebral body.

gus relative to the midline of the cricoid was $3.3 \mathrm{~mm}$ \pm SD $1.3 \mathrm{~mm}$ (range $1.4 \mathrm{~mm}$ to $5.7 \mathrm{~mm}$ ). In the population with lateral esophageal displacement, $64 \%$ had esophageal displacement beyond the lateral border of the cricoid (mean $3.2 \mathrm{~mm} \pm \mathrm{SD} 1.2 \mathrm{~mm}$; range 1.4 $\mathrm{mm}$ to $5.7 \mathrm{~mm}$ ). The percentage of displaced esopha-

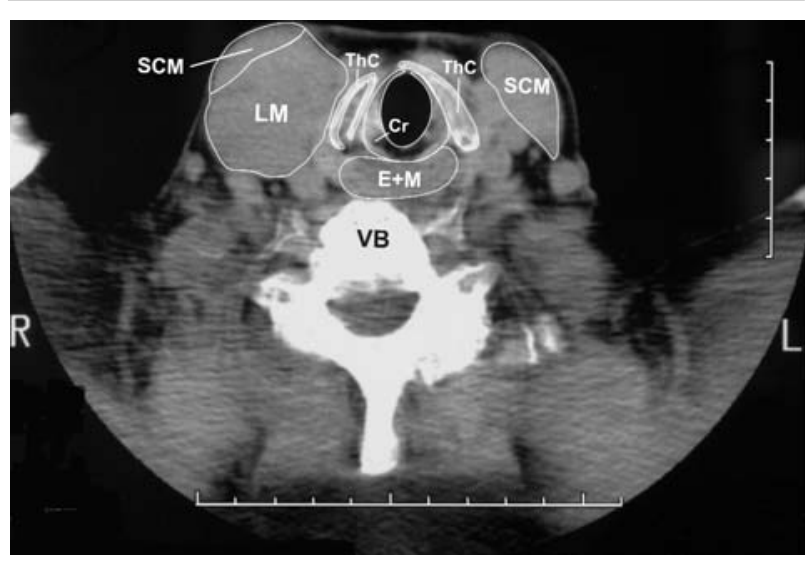

FIGURE 5 Computed tomography of the neck and line drawing demonstrating a large right-sided lymphoma causing significant leftward displacement of the esophagus-constrictor muscle complex. $\mathrm{Cr}=$ cricoid cartilage; $\mathrm{E}+\mathrm{M}=$ esophagus-inferior constrictor muscle complex; $\mathrm{LM}=$ lymphomatous mass $; \mathrm{SCM}=$ sternocleidomastoid muscle; $\mathrm{ThC}=$ thyroid cartilage; $\mathrm{VB}=$ vertebral body.

gus relative to the total esophageal diameter displays a normal distribution (Figure 1). Of those with displacement, $48 \%$ had over $15 \%$ of the total width of the esophagus displaced laterally and $20 \%$ had over $20 \%$ of the esophageal width displaced laterally.

Figure 2 is a CT scan of a neck demonstrating 1.5 $\mathrm{mm}$ of lateral esophageal displacement. From the set of CT scans that were excluded, Figures 3 and 4 demonstrate necks with nearly complete esophageal displacement due to an unsuspected vertebral body osteophyte and compression from a thyroid tumour, respectively. Figure 5 demonstrates a neck with over $50 \%$ the diameter of the esophagus displaced laterally due to a large right-sided lymphoma.

\section{Discussion}

The effectiveness of $\mathrm{CP}$ relies on direct compression of the esophageal lumen, thereby preventing the passage of regurgitant gastric contents into the oropharynx. Therefore, knowledge of the anatomical relationship between the cricoid and the esophagus is crucial to understand reported successes and failures. Based on anatomy and common sense, an assumption has been made since Sellick introduced the technique of cricoid pressure in 1961: the esophagus lies directly posterior to the cricoid. While this relationship has been assumed to be true in the majority of the population, we have identified some degree of lateral esophageal displacement in 25 of 51 subjects. Based on our sample size, the lower and upper $95 \%$ confidence limits are 
$35.3 \%$ and $62.7 \%$ respectively for our estimated frequency of $49 \%$.

Since the esophageal lumen cannot reliably be visualized on CT scans of the neck, we are unable to determine the proportion of unopposed esophageal lumen. Furthermore, due to the limitations of CT images in defining soft-tissue structures, we are unable to differentiate the esophagus from the inferior pharyngeal constrictor muscle surrounding the opening of the esophagus on several images. However, based on anatomical knowledge, the constrictor muscle is positioned symmetrically around the midline. Lateral displacement of the constrictor muscle together with the esophagus would likely be as significant as displacement of the esophagus alone. Therefore, the position of the esophagus was assumed to be in the midline of the constrictor muscle on those images.

The clinical significance of 1.4 to $5.7 \mathrm{~mm}$ of lateral esophageal displacement or the proportion of the diameter of the esophagus required to be occluded to prevent regurgitation is uncertain. However, a $49 \%$ frequency of lateral displacement offers important information for further debate on the use of CP.

Although excluded from our study based on the presence of pathology, we identified several individuals with pathology causing such significant esophageal displacement that it would appear that $\mathrm{CP}$ would be ineffective (Figures 3 to 5 ). It is possible that individuals with large thyroid tumours or lymphomatous masses in the neck may have a high prevalence of significant lateral esophageal displacement. The application of CP in these individuals might not only be ineffective but may also increase the distortion of airway anatomy, thereby creating sub-optimal or perhaps difficult intubating conditions.

Also of interest was the finding of large anterior vertebral osteophytes in some individuals that resulted in lateral esophageal displacement. As demonstrated in Figure 3, CP may be completely ineffective in this individual since the entire esophagus lies lateral to the vertebral body. Although the technology and resources to identify individuals with this type of pathology prior to the induction of anesthesia are not currently practical or likely available, diagnostic imaging could prevent the unnecessary use of $\mathrm{CP}$ and the possibility of complications associated with its application. However, routine imaging cannot be advocated when one considers the relatively low frequency of significant pulmonary aspiration during general anesthesia. Large case series suggest frequencies of aspiration ranging from $\mathrm{l}$ in 3886 during elective surgery to 1 in 895 during emergency surgery. ${ }^{10}$

The technique of CP has been considered a necessary component of rapid sequence induction per- formed in patients at high risk for passive gastric regurgitation and aspiration with the induction of general anesthesia for at least 40 years. However, previous reports of its failure to prevent regurgitation have never been explained adequately. Its use has also been associated with serious complications including distorted laryngeal view, increased difficulty with intubation, laryngeal trauma, cricoid fracture, and esophageal rupture. ${ }^{11-15}$ To date, there has never been a randomized, controlled study assessing the effectiveness of CP. Schreiner has pointed out the difficulty of conducting such a study given the low event rates for regurgitation and pulmonary aspiration. ${ }^{16}$ Large, welldesigned case-control studies would be the most feasible manner to assess both the efficacy and potential harm of CP.

Our study illustrates the anatomical variation seen in patients in the absence of CP. We are unable to draw conclusions regarding the efficacy of $\mathrm{CP}$ from our observations. We are currently undertaking another imaging study to explore the anatomical relationship between the cricoid and the esophagus during application of CP. In summary, nearly half of all patients in our study had some degree of lateral displacement of the esophagus relative to the cricoid. In addition to the mechanisms listed previously, anatomical variation may potentially explain some reported failures of $\mathrm{CP}$ to prevent regurgitation during the induction of anesthesia. We suggest that the efficacy of $\mathrm{CP}$ and the reasons for observed failures merit further investigation.

\section{References}

1 Sellick $B A$. Cricoid pressure to prevent regurgitation of stomach contents during induction of anaesthesia. Lancet $1961 ; 2$ : 404-6.

2 Brimacombe JR, Berry AM. Cricoid pressure. Can J Anaesth 1997; 44: 414-25.

3 Rosen M. Anaesthesia for obstetrics. Anaesthesia 1981; 36: 145-6.

4 Schwartz DE, Cohen NH. Questionable effectiveness of cricoid pressure in preventing aspiration (Letter). Anesthesiology 1995; 83: 432.

5 Kron SS. Questionable effectiveness of cricoid pressure in preventing aspiration (Letter). Anesthesiology 1995; 83: 431 .

6 Howells TH, Chamney AR, Wraight WJ, Simons RS. The application of cricoid pressure. An assessment and a survey of its practice. Anaesthesia 1983; 38: 457-60.

7 Herman NL, Carter B, Van Decar TK. Cricoid pressure: teaching the recommended level. Anesth Analg 1996; 83: 859-63.

8 Meek T, Gittins N, Duggan JE. Cricoid pressure: 
knowledge and performance amongst anaesthetic assistants. Anaesthesia 1999; 54: 59-62.

9 Vanner RG, Pryle BJ. Nasogastric tubes and cricoid pressure (Letter). Anaesthesia 1993; 48: 1112-3.

10 Warner MA, Warner ME, Weber JG. Clinical significance of pulmonary aspiration during the perioperative period. Anesthesiology 1993; 78: 56-62.

11 Hartsilver EL, Vanner RG. Airway obstruction with cricoid pressure. Anaesthesia 2000; 55: 208-11.

12 Heath KJ, Palmer M, Fletcher SJ. Fracture of the cricoid cartilage after Sellick's manoeuvre. Br J Anaesth 1996; 76: 877-8.

13 Allman KG. The effect of cricoid pressure application on airway patency. J Clin Anesth 1995; 7: 197-9.

14 Ralph SJ, Wareham CA. Rupture of the oesophagus during cricoid pressure. Anaesthesia 1991; 46: 40-1.

15 Lawes EG, Campbell I, Mercer D. Inflation pressure, gastric insufflation and rapid sequence induction. $\mathrm{Br} \mathrm{J}$ Anaesth 1987; 59: 315-8.

16 Schreiner MS. Gastric fluid volume: is it really a risk factor for pulmonary aspiration? Anesth Analg 1998; 87: 754-6.

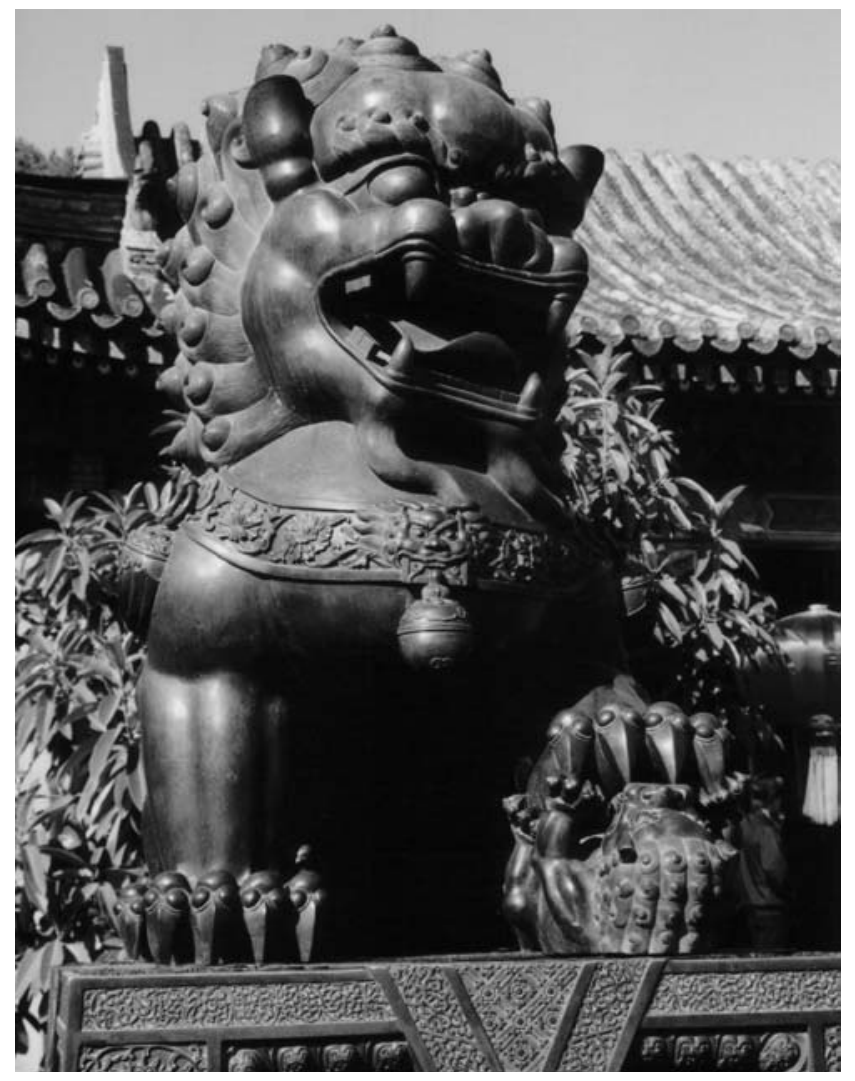

Traditional entrance lion - China 